Disturbance of the cytokine equilibrium has been accused for many pathological disorders. Microbial infections, autoim mune diseases, graft rejection have been correlated to over-or under-production of specific cytokines which are produced as responder molecules to the various immune stimuli. The sole naturally occurring im mune reaction in the organ is $m$ is developed during the gestational period where, despite the presence of a semi-allogeneic graft, maternal immunoreactivity is driven to support fetal growth. The successful embryo development has been attributed to the important intervention of cytokines where some have been characterized as indispensable and others deleterious to fetal growth. However, the physiological levels of many factors during the gestational process have not been determined. Thus, in the present study we have measured and established the values of IL-1 $\alpha$, IL-2, IL-3, IL-4, IL6, IL-10, IL-12, GM-CSF, TNF- $\alpha$ and IFN- $\gamma$ during all phases of human pregnancy (first, second and third trimester of pregnancy, labour, abortions of the first trimester) as well as in the non-pregnant control state. This is an attempt to assess serum protein concentrations and present the physiological levels of these cytokines at certain time intervals providing thus a diagnostic advantage in pregnancy cases where the mother cannot immunologically support the fetus. Exploitation of this knowledge and further research may be useful for therapeutic interventions in the future.

Key words: IL-1 $\alpha$, IL-2, IL-3, IL-4, IL-6, IL-10, IL-12, GMCSF, $\mathrm{TNF}-\alpha$, IFN- $\gamma$, Non-pregnant state, Abortions, Trimesters of pregnancy, Labour, Immunological implication in reproduction

\section{Serum levels of pro- and anti-inflammatory cytokines in non-pregnant women, during pregnancy, labour and abortion}

\author{
S. Vassiliadis, ${ }^{1,3, \mathrm{CA}}$ A. Ranella, ${ }^{1}$ L. Papadimitriou, ${ }^{1}$ \\ A. Makrygiannakis ${ }^{2}$ and I. Athanassakis ${ }^{1}$
}

${ }^{1}$ Department of Biology, and ${ }^{2}$ Department of Medicine, Division of Gynaecology, University of Crete, Heraklion, and ${ }^{3}$ Immunology Centre for Pregnancy, Heraklion, Crete, Greece

\footnotetext{
${ }^{\mathrm{CA}}$ Corresponding Author

Tel: $(+30) 081394355$

Fax: (+30) 081243656

Email: simon@biology.uch.gr
}

\section{Introduction}

Despite the unique ability of the immune system to highly specific antigen recognition, its susceptibility to cytokines allows these molecules to dominate all kinds of immune reactions. These proteins, produced in an autocrine or paracrine fashion, bind to specific receptors initiating thus a cascade of reactions on different targets having beneficial or harmful effects since their redundancy and/or pleiotropic nature may account for all possible reactions. With T helper (Th) lymphocytes being the major producers of cytokines, it is believed that the equilibrated balance of Th1 versus Th2 cytokines defines the welfare of the organism. ${ }^{1,2}$ The immune system, in order to ensure protection from microbial infections, autoimmune reactions, graft rejection, allergies, etc., leans the balance towards one or the other family of cytokines.

Pregnancy is a natural example of an immune reaction occurring for a determined time period in the organism which opposes the rules of graft rejection. The semi- or allogeneic fetal components growing in the privileged site of uterus, not only escape maternal immune attack but are supported by the maternal immune system. An important role in the maintenance of pregnancy is played by cytokines, where successful fetal outcome is correlated to the production of Th2 cytokines and fetal rejection to Th1 cytokines. Although the protective role of the Th2 cytokine IL-10 during mid-gestation, ${ }^{3}$ as well as the harmful effects of Th1 cytokines IL- $2,{ }^{4} \mathrm{TNF}-\alpha^{5-7}$ and IFN- $\gamma^{5,8}$ have been demonstrated in mice, other studies show that each cytokine follows a specific pattern of expression each day of pregnancy in mice.? These observations indicate that despite the beneficial or harmful effect of a cytokine during a specific time course of the gestational cycle, a determined upor downregulation of these factors must be followed, pattern that will decide for the successful or not outcome of pregnancy. It becomes thus mandatory to define the physiological levels of cytokines during 
human pregnancy, which may finally have a prognostic character for the outcome of pregnancy.

In the present report, we examined the serum levels of 10 cytokines during the first, second and third trimesters of pregnancy, before pregnancy and labour and compared the values of physiological first trimester of pregnancy with cases of fetal rejection.

\section{Materials and Methods}

\section{Patients}

After informed consent of all patients, we analysed the serum of 15 non-pregnant-state women, the serum of 19,17 and 18 first, second and third trimester women respectively, the serum of 15 women in labour and 19 women who underwent spontaneous abortion. All sera, isolated from $5 \mathrm{ml}$ peripheral blood, were provided by the Division of Gynaecology of the University Hospital (Heraklion, Crete).

\section{Reagents and cytokine determination}

Cytokine detection in the serum was achieved by commercial kits purchased from Endogen (Cambridge, MA, USA; IL-1 $\alpha$, IL-2, IL- 4 , IL-6, IL-10, GM-CSF, TNF- $\alpha$, IFN- $\gamma$ ) and R\&D systems (Oxfordshine, UK; IL-3, IL12). Serum cytokine measurement was performed using an ELISA method as specified by the suppliers at test and reference wavelengths of 450 and $550 \mathrm{~nm}$ respectively. The results are expressed in $\mathrm{ng} / \mathrm{ml}$ and were compared with standard curves obtained from titrations of the corresponding recombinant factors provided by the suppliers. The Endogen ELISA kits for IL-1 $\alpha$, IL 4 , GM-CSF and IFN- $\gamma$ detect $<2 \mathrm{pg} / \mathrm{ml}$ of the equivalent protein, whe reas the IL-2 kit detects $<6 \mathrm{pg} /$ $\mathrm{ml}$, IL- $6<1 \mathrm{pg} / \mathrm{ml}$, IL- $10<3 \mathrm{pg} / \mathrm{ml}$ and TNF $-\alpha<5 \mathrm{pg} / \mathrm{ml}$. The R\&D Systems EUISA kits for IL-3 and IL-12 detect 7.4 and $5 \mathrm{pg} / \mathrm{ml}$ of protein respectively. In all cases the above values given for the lower limit of detection is the smallest dose of protein that is not zero with $95 \%$ confidence. Both manufacturers guarantee the specificity of each individual kit.

\section{Statistical analysis}

Since the abortions studied occurred during the first trimester of pregnancy, the Student's $t$-test was employed in order to compare the significance levels $(P)$ between the abortion values of the different cytokines and those of the actual first trimester of gestation. In this particular group of analysis all $P$ values equal or lower than 0.025 are considered to be non-significant. Degrees of freedom: $18(n-1)$.

\section{Results and Discussion}

Cytokine levels in the serum seem to reflect the pathologic state of the organism and may, in many cases, have a prognostic character for therapy subscription. In this study, concentrating our interest to human pregnancy where the rates of fetal rejection dangerously increase, we define the physiological levels of 10 different cytokines before, during and after pregnancy.

\section{Assessment of cytokine levels during pregnancy and in the non-pregnant state}

The goal of this work was to determine the actual (physiological) levels of diverse cytokines during pregnancy. For this, serum from non-pregnant women as well as during the first, second and third trimester of pregnancy and labour was collected and analysed by ELISA as to the cytokine content. In addition, serum from women who underwent abortion during the first trimester of their pregnancy was also examined and the same cytokines were evaluated. Table 1 thus presents the physiological values of the

Table 1. Physiological cytokine values in human non-pregnant and pregnant state

\begin{tabular}{|c|c|c|c|c|c|}
\hline \multirow[t]{2}{*}{ Cytokine } & \multicolumn{5}{|c|}{ Cytokine levels ( $\mathrm{ng} / \mathrm{ml} \pm$ SEM) during the following states } \\
\hline & $\begin{array}{l}\text { Non-pregnant } \\
\text { state }\end{array}$ & 1st trimester & 2nd trimester & 3rd trimester & Labour \\
\hline $\begin{array}{l}\text { IL-1 } \\
\text { IL-2 } \\
\text { IL-3 } \\
\text { IL-4 } \\
\text { IL-6 } \\
\text { IL-10 } \\
\text { IL-12 } \\
\text { GM-CSF } \\
\text { TNF- } \alpha \\
\text { IFN- } \gamma\end{array}$ & $\begin{array}{l}1.76 \pm 0.40 \\
3.60 \pm 0.30 \\
3.80 \pm 0.40 \\
0.16 \pm 0.01 \\
2.70 \pm 0.30 \\
0.77 \pm 0.02 \\
0.83 \pm 0.11 \\
2.70 \pm 0.25 \\
0.62 \pm 0.04 \\
1.07 \pm 0.14\end{array}$ & $\begin{array}{l}1.73 \pm 0.53 \\
3.63 \pm 0.60 \\
3.85 \pm 0.52 \\
0.14 \pm 0.02 \\
2.55 \pm 0.24 \\
0.76 \pm 0.07 \\
0.79 \pm 0.10 \\
2.78 \pm 0.28 \\
0.60 \pm 0.06 \\
1.06 \pm 0.08\end{array}$ & $\begin{array}{l}1.55 \pm 0.34 \\
3.56 \pm 0.46 \\
3.36 \pm 0.54 \\
0.16 \pm 0.05 \\
2.91 \pm 0.38 \\
0.74 \pm 0.09 \\
0.85 \pm 0.27 \\
3.01 \pm 0.32 \\
0.57 \pm 0.09 \\
1.14 \pm 0.11\end{array}$ & $\begin{array}{l}1.89 \pm 0.42 \\
3.41 \pm 0.61 \\
3.32 \pm 0.55 \\
0.17 \pm 0.04 \\
2.91 \pm 0.34 \\
0.88 \pm 0.10 \\
0.80 \pm 0.08 \\
3.14 \pm 0.73 \\
0.60 \pm 0.07 \\
1.33 \pm 0.14\end{array}$ & $\begin{array}{l}1.76 \pm 0.70 \\
3.23 \pm 0.96 \\
3.60 \pm 0.46 \\
0.15 \pm 0.01 \\
2.87 \pm 0.31 \\
0.96 \pm 0.11 \\
0.73 \pm 0.03 \\
3.52 \pm 0.57 \\
0.62 \pm 0.03 \\
1.35 \pm 0.20\end{array}$ \\
\hline$n$ & 15 & 19 & 17 & 18 & 15 \\
\hline
\end{tabular}


cytokines studied. In the course of this analysis we detected statistically significant $(P<0.05$ to $P<$ $0.001)$ differences between the non-pregnant state and pregnancy for IL-1 $\alpha$ (drop in second trimester by $13 \%$ ), IL-2 (decrease mainly at labour by $11 \%$ ), IL-3 (decrease at second and third trimester by 14\%), IL-10 (increase at labour by 28\%), GM-CSF (increase at third trimester and labour by $16 \%$ and $30 \%$ respectively) and IFN- $\gamma$ (increase at third trimester and labour by $25 \%$ and $26 \%$ respectively).

By the same token, significant differences within the different pregnancy stages are obtained by IL-1 $\alpha$ (minimal production in the second trimester), IL-2 (decrease in third trimester and labour), IL-3 (decrease after the first trimester), IL-6 (increase after the first trimester), IL-10 (increase during labour), GM-CSF and IFN- $\gamma$ (steady increase after the first trimester).

TNF- $\alpha$, accused for pregnancy failure,${ }^{5-7}$ presents a stable production profile in all stages. The same is also shown for IL-12, a factor that has been reported as an immunomodulator in various mechanisms during pregnancy. ${ }^{10-12}$ Finally, IL-10 and IL 4 , named as protective agents during pregnancy, 3,13 show a constant presence at the first two trimesters with IL-10 showing a peak of production during labour (as stated above). These four cytokines show a minimal presence in the serum of pregnant or non-pregnant women at levels ranging from 0.88 to $0.14 \mathrm{ng} / \mathrm{ml}$, implying a possible maintenance role during the gestation period.

\section{Assessment of cytokine levels in the first trimester abortions}

The serum from women who aborted during their first trimester was also examined for the same cytokine content and the corresponding values were determined. Table 2 shows not only the cytokine values of aborted women but also a statistical comparison with the actual values (taken from Table 1) of women in their first trimester of continuing pregnancy. It is shown that although there are no differences for IL 4 , IL- 12 and TNF- $\alpha$ (we consider $P \leq 0.025$ as not significant, as stated in the Methods), the situation with the remaining cytokines is totally different. Whilst only the IL-1 $\alpha$ and IL-3 levels drop during abortion (IL-1 $\alpha$ not significantly by $8 \%$ or $P<0.3$ but with a considerable $17 \%$ decrease in IL-3), on the contrary, IL-2, IL6, IL-10, GM-CSF and IFN- $\gamma$ levels increase when abortion occurs with IFN- $\gamma$ being more obvious in magnitude (53\% of increase). Although it is not clear yet whether increase in cytokine production is responsible for the abortion process or it is the abortion itself that modulates cytokine levels, this latter observation gives an insight to and supports the Th1 versus Th2 situation in pregnancy. It is seen
Table 2. Cytokine levels during abortions occurred at the first trimester of pregnancy

\begin{tabular}{lcc}
\hline Cytokine & $\begin{array}{c}\text { Cytokine levels } \\
\text { (ng/ml } \pm \text { SEM) } \\
\text { during abortion } \\
\text { in the 1st trimester }\end{array}$ & $\begin{array}{c}\text { Statistical level of } \\
\text { significance }(P) \\
\text { compared with 1st } \\
\text { trimester values }\end{array}$ \\
\hline IL-1 & $1.60 \pm 0.46$ & $P<0.3$ (NS; decrease 8\%) \\
IL-2 & $4.05 \pm 1.24$ & $P<0.005$ (increase 12\%) \\
IL-3 & $3.28 \pm 0.41$ & $P<0.001$ (decrease 17\%) \\
IL-4 & $0.15 \pm 0.01$ & $P<0.025$ (NS; increase 7\%) \\
IL-6 & $2.95 \pm 0.40$ & $P<0.001$ (increase 15\%) \\
IL-10 & $0.87 \pm 0.06$ & $P<0.001$ (increase 14\%) \\
IL-12 & $0.80 \pm 0.05$ & $P<0.6$ (NS; increase 1\%) \\
GM-CSF & $3.40 \pm 0.02$ & $P<0.001$ (increase 22\%) \\
TNF- $\alpha$ & $0.63 \pm 0.04$ & $P<0.025$ (NS; increase 5\%) \\
IFN- $\gamma$ & $1.62 \pm 0.16$ & $P<0.001$ (increase 53\%) \\
$n$ & 19 & 19 \\
\hline
\end{tabular}

$P \leq 0.025$ levels are considered to be non-significant (NS).

Degrees of freedom: $18(n-1)$.

$n$. Number of cases in each category.

here that Th1 cytokine levels are augmented during abortion whereas, Th2 are not significantly different or dropping. Another point that merits attention is the IFN- $\gamma$ increased levels during abortion. This piece of data confirms previous reports and strengthens the correlation between this agent and fetal rejection. ${ }^{7}$

The results presented here do not differ from the recently published report by Tranchot-Diallo et al. ${ }^{14}$ where modulation of cytokine ge ne expression (TNF$\alpha$, IFN- $\gamma$, GM-CSF, IL-1 $\beta$, IL-2, IL- 4 , IL-6 and IL-10) by RT-PCR in pregnancy was evaluated.

\section{References}

1. Miossec P. Acting on the cytokine balance to control autoimmunity and chronic inflammation. Eur Cyt Netw 1993; 4: 245-251.

2. Charlton B, Lafferty KJ. The Th1/Th2 balance in autoimmunity. Curr Opin Immunol 1995; 7: 793-798.

3. Chaouat G, Melani A, Martal J, Raghupathy R, Elliot J, Mossmann T, Wegmnan TG. IL-10 prevents naturally occurring fetal loss in $\mathrm{CBA} \times \mathrm{DBA} /$ 2 mating combination and local defect in IL-10 production in this abortion-prone combination is corrected by in vivo injection of IFN- $\tau$. $J$ Immunol 1995; 154: 4621-4629.

4. Tezabwala BU. Inhibition of pregnancy viability in mice following IL-2 administration. Immunology 1989; 67: 115-120.

5. Chaouat G, Menu E, Bustany P, Rebut-Bonneton C, Szekeres-Bartho J, Wegmann TG. Role du placenta dans le maintien de l'allogreffe fetale. Reprod Nutr Devel 1988; 28: 1587-1598 (in French).

6. Kohchi C, Mizuno DI, Soma GI. Expression of tumor necrosis factor- $\alpha$ and $\beta$ transcripts in embryonal carcinoma and trophoblast cell lines: inflammation Hike state as possible regulatory mechanism for ontogenesis. Eur Cyt Netw 1991; 2: 245-255.

7. Shaarawy M, Nagui AR. Enhanced expression of cytokines may play a fundamental role in the mechanisms of immunologically mediated recurrent spontaneous abortion. Acta Obstet Gynecol Scand 1997; 76: 205-211.

8. Vassiliadis S, Tsoukatos D, Athanassakis I. Interferon-induced class II expression at the spongiotrophoblast zone of the murine placenta is linked to fetal rejection and developmental abnormalities. Acta Physiol Scand 1994; 151: 485-495.

9. Athanassakis I, Iconomidou B. Cytokine production in the serum and spleen of mice from day 6 to 14 of gestation. Dev Immunol 1996; 4: 247-255.

10. Dudley DJ, Hunter C, Mitchell MD, Varner MW, Gately M. Elevations of serum IL-12 concentrations in women with severe pre-eclampsia and HELP syndrome. J Reprod Immunol 1996; 31: 97-107. 
11. Seder RA, Gazzinelli R, Sher A, Paul W. Interleukin-12 acts directly on $\mathrm{CD} 4+\mathrm{T}$ cells to enhance priming for interferon- $\gamma$ production and diminishes interleukin 4 inhibition of such priming. Proc Natl Acad Sci USA 1993; 90: 10188-10192.

12. Tripp CS, Wolf SF, Unanue ER. Interleukin-12 and tumor necrosis factor- $\alpha$ are costimulators of interferon- $\gamma$ production by natural killer cells in severe combined immunodeficiency mice with listeriosis, and interleukin-10 is a physiologic antagonist. Proc Natl Acad Sci USA 1993; 90 . 3725-3729.

13. Ekerfelt C, Matthiesen L, Berg G, Erneudh J. Paternal leucocytes selectively increase secretion of IL 4 in peripheral blood during normal pregnancies: demonstrated by a novel one-way MLC measuring cytokine secretion. Am J Reprod Immunol 1997; 38: 320-326.
14. Tranchot-Diallo J, Gras G, Parnet-Mathieu F, Benveniste O, Marce D, Roques P, Milliez J, Chaouat G, Dormont D. Modulations of cytokine expression in pregnant women. Am J Reprod Immunol 1997; 37: 215-226.

ACKNOWLEDGMENTS. This work was funded by the Greek Secretariat of Research and Technology under the framework of the EPET II programme (PENED).

\section{Received 7 November 1997;}

accepted in revised form 11 November 1997 


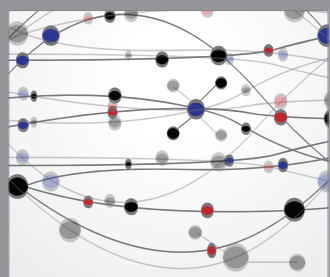

The Scientific World Journal
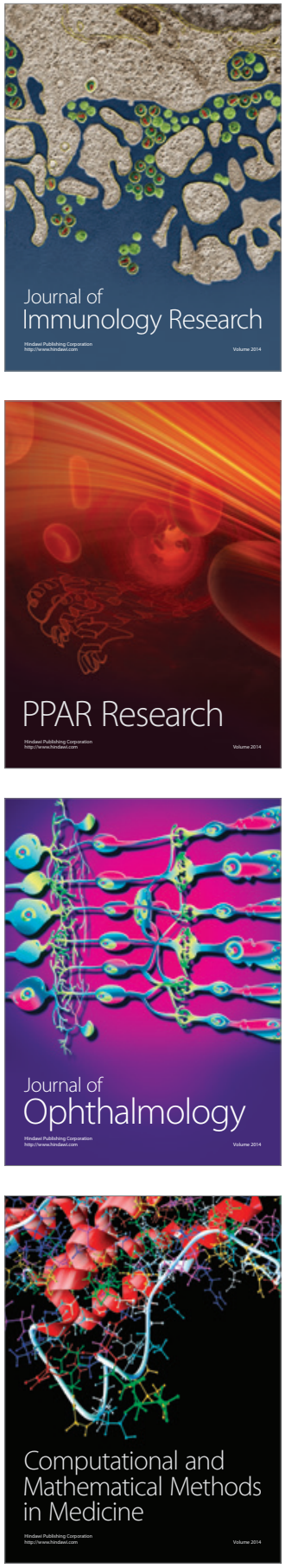

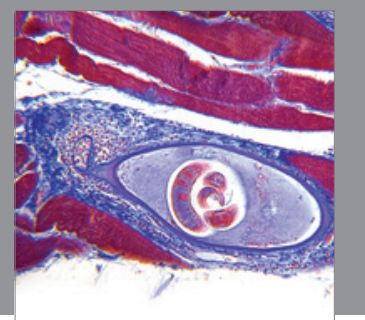

Gastroenterology

Research and Practice
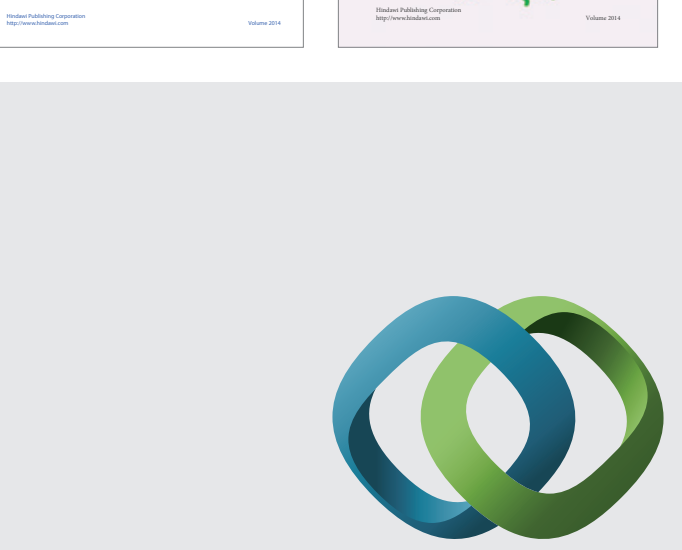

\section{Hindawi}

Submit your manuscripts at

http://www.hindawi.com
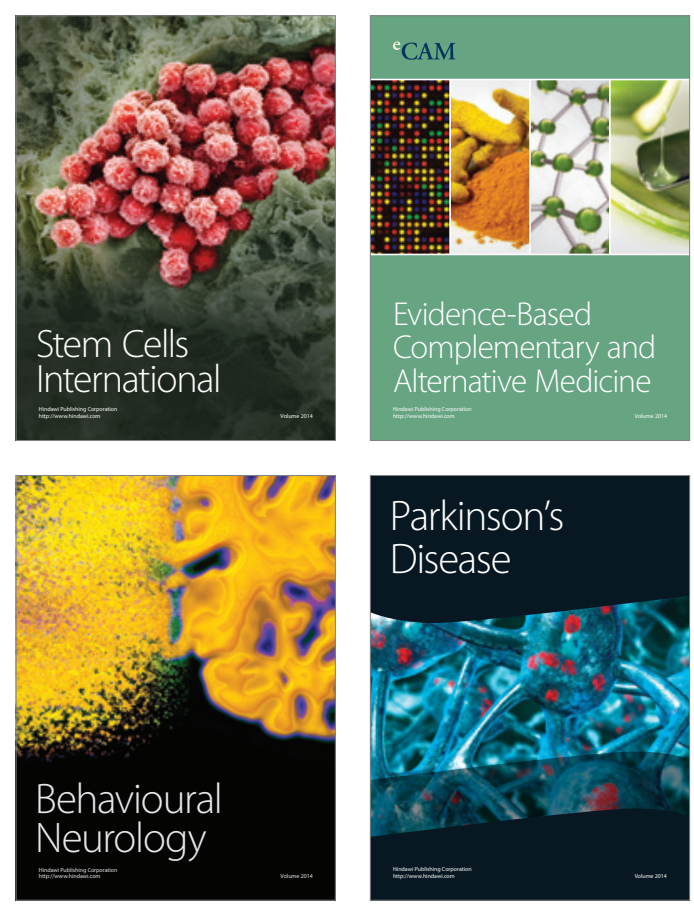

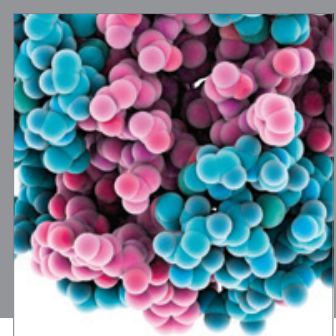

Journal of
Diabetes Research

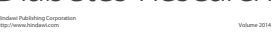

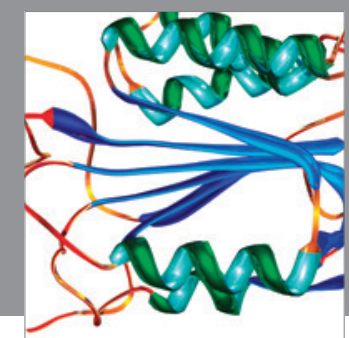

Disease Markers
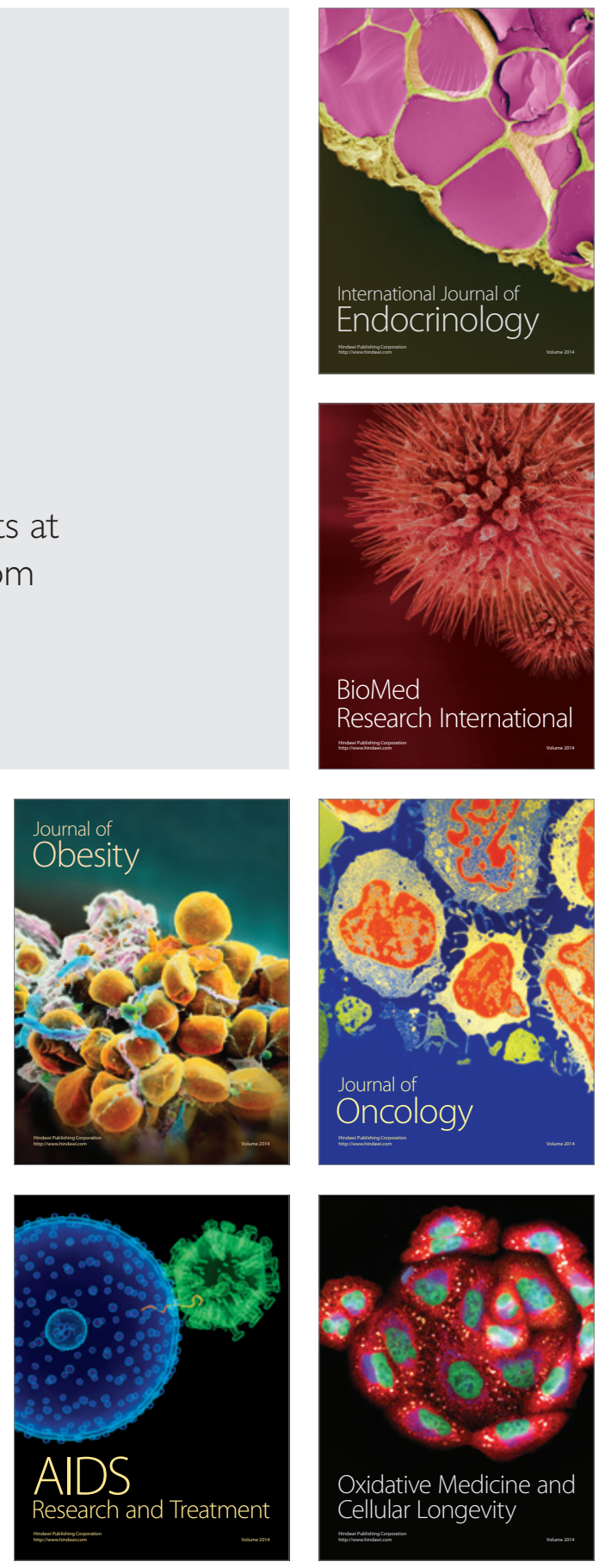